\title{
AN ALTERNATIVE STRATEGY TO ANALYZE THE CONTENTS OF BIOCHEMISTRY INTRODUCTORY COURSES
}

\author{
Miskalo, A.K., Torres, B.B. \\ Departamento de Bioquímica, Instituto de Química, Universidade de São \\ Paulo, São Paulo, Brasil.
}

A common problem educators from different areas face is to fit the increasing amount of information with the maintenance and/or, not seldom, a decrease in the class load of their courses. This actual situation necessarily forces the educator to severely select the topics to be worked out. In the current scenario of most teaching institutions, this decision is taken by the teacher. In order to do this, a list of the topics considered to be essential for an appropriate biochemistry course is necessary. Taking for granted that questions from biochemistry courses tests reflect the topics considered most relevant by teachers, questions from different courses offered by Biochemistry Department of USP were analyzed. The objective of this analysis was to answer two main questions, namely (1) Which is the extent and depth of the common topics in biochemistry introductory courses? and (2) Are there (and, if there are, which are they?) specific topics for different careers? The method we adopted was to verify the demanded topics in written tests and to classify their cognitive level according to Bloom's Taxonomy. The most recurring topics found are Protein Structure and Metabolism Regulation. The results indicate a strong predominance of low-level categories (Knowledge e Comprehension), with little occurrence of high-level categories (from Application on). It is expected, from further development of this study, to outline the topics considered relevant to set the basis for the discussion on the establishment of a minimum curriculum for biochemistry courses.

Key words: Bloom's Taxonomy, minimum curriculum, written tests analysis. 